Culture, Curriculum, and Identity in Education H. Richard Milner (Ed.) (2010). NY: Palgrave Macmillan. 232 Pages. ISBN: 978-0-230-62204-3

Identity involves different facets of human self-definition and is unequivocally a vital element of individuals' lives, especially in diverse societies. Culture and identity are intertwined. In education, culture in the curriculum plays a vital component in students' identity formations. Supportive school environments provide socially, culturally and linguistically appropriate curricula that legitimize identity formations. Teachers and the curricula they teach are sources of identity formation. Every classroom encounter is largely dictated by the teacher's role and the perception the teacher has of the students.

Richard Milner's Culture, curriculum, and identity in education is an edited book that is rich in transformative discourse that reveals the connections between culture, curriculum and identity in schools and teacher education programs. The book is a collection of well written and interconnected discussions and research papers that critically analyze the marginalization of minority groups in the North American education system, particularly in the United States (US). The book is well structured and organized in four sections: Identity and P through 12 Curriculum in Multiple Contexts (part 1); Culture, Curriculum, and Identity with Implications for EnglishLanguage Learners and Immigration (part 2); Spirituality as Identity with Implications for research and Teaching (part 3); and Culture, Curriculum, and Identity with Implications for Teacher Education (Part 4). Although the book is divided into these sections, there is a continuous loop that connects these sections to the main theme of the book. The authors of the chapters maintain a similar argument that the curriculum content, language-in-education, schools, classrooms, teachers, and teacher educators need to be transformed in order to address diverse student populations that are in US and Canadian schools. They argue that the conservative Eurocentric epistemological and ontological foundations in the curriculum content and schools do not reflect the multiplicity of voices and contexts students and that the existing linguistic and cultural hegemonic ideologies and practices cripple the vision and academic outcomes of students from marginalized communities. The authors advocate for equity and diversity in schools and teacher education programs which should be addressed through a reformative agenda that takes into account the languages, culture, spirituality and humanity of visible minority teachers.

In Chapter 1, Eric Toshalis discusses the identity-perception gap between White teachers and visible minority students. The identity-perception gap is detrimental to students who may not share the same cultural, racial, linguistic, gender and social class traits with their teacher. Identity perceptions have been found to negatively affect students. One consequence of negative identity formation in the classroom is the tendency to silence adolescents who are at a vulnerable stage in their development. Dialogue or voice is the basis of most classroom activities, and it enables students to share their thoughts and experiences with other students and the teacher (Shizha, 2005). Toshalis aptly, with examples, discusses the difficulties and vulnerabilities (discomfort and confusion) that both teachers and students experience because of the differences in their identity-perceptions. Identity-perception gap that is not negotiated may result in White teachers labeling, dismissing, and 'otherizing", or stigmatizing students from visible minority backgrounds as inferior. Toshalis recommends that the identity-perception gap should be considered as a resource for further engagement, exploration, and understanding. However,

Cultural and Pedagogical Inquiry, 2011, 3(2), pp.42-46

ISSN 1916-3460 @ 2011 University of Alberta

http://ejournals.library.ualberta.ca/index.php/cpi/index 
Toshalis overlooks the negative effect of vulnerability. Anxiety and anger neither lead to positive identity formation nor to caring school/classroom situations that are adaptive to the social and cultural heterogeneity of students. Teachers and teacher educators should focus on reducing the identity-perception gap and making students appreciate that they learn positively by acknowledging and sharing their rich experiences.

In chapter 2, Richard Milner addresses the application of a multicultural curriculum to "build bridges and to unite diverse groups from various life worlds" (p.39). What is critical in his exposition is a convincing presentation of the advantages of multiple experiences in a multicultural curriculum for students and teachers alike. An inclusive curriculum is likely to improve not only the academic success of minority students but also reduce the disconnections and misrepresentations that are historically presented in the curriculum. A redefinition of curriculum knowledge, curriculum development and implementation is a necessary process for transforming the predominantly white learning contexts that are the major feature of the learning process in North America. Milner (citing Sleeter \& Grant, 1994; McAllister \& Irvine, 2000; Banks, 1998) explores the process and benefits of a social reconstructionist curriculum that incorporates the contributions approach, the additive approach, the transformative approach and the social action approach (p.43). The benefits include social action that integrates cultural expectations and cultural scripts relevant for the development of self-expression and a "connected mind, voice and emotion" (Bosacki, 2005, p. 6).

Undoubtedly, language use in schools is a sociopolitical issue. Irizarry and Raible (chapter 4), argue that the sociopolitical context that surrounds English-language learners (ELLs) is a great impediment to participation by students in the classroom. The authors support their arguments by citing relevant literature such as Les Back (1996) who suggested that the ELLs' "muted voices must be integrated into any understanding of the contemporary politics of culture and identity" (p.95). Irizarry and Raible warn teachers who ignore the silenced voices that they are doing a social injustice to the collective struggles of the oppressed that are fighting for cultural survival and educational equity. The authors advise teachers to be multicultural educators who take into account the history of the oppressed: African Americans, Hispanics and American natives in order to recognize their cultural and linguistic distinctiveness when designing educational programs.

In chapter 5, Carl James argues that schools transmit conservative middle-class culture. He acknowledges the complexities and challenges the working-class students of immigrant parents encounter. He gives examples of schools attended by immigrant students in "immigrant enclaves" in Toronto where Black students are stereotyped as being dangerous, are racially profiled and stigmatized because of their race. James uses narratives from youths in these poor communities to establish and conclude that community plays a vital role in the lived experiences and expectations of young people. For him, social class, social and cultural capital, and community wealth are determinants of educational aspiration and success. The Eurocentric ideology that is reproduced by the education system disadvantages students from immigrant, racialized and ethnic minorities.

The role of spirituality in identity formations and its implications for research and teaching is an area that has hardly been studied. Michael Dantley, in chapter 6, and Stephen Hancock in chapter 7 , criticize grand narratives and positivism for being hegemonic in their Cultural and Pedagogical Inquiry, 2011, 3(2), pp.42-46 ISSN 1916-3460 @ 2011 University of Alberta http://ejournals.library.ualberta.ca/index.php/cpi/index 
prescription of what is considered "legitimate" research (p.143). For these authors quantitative research does not celebrate diversity, cultural sensitivity and transformative-emancipatory research. Citing Stanley (2007), Dantley notes that the grand narrative is "a script that specifies and controls how social processes are carried out." Dantley accurately, and justifiably so, argues that grand narratives are essentialized and reified and ignore the foundations of social constructionism in the social creation of reality. Dantley cites Richard Milner, Cynthia Dillard, and Patty Lather as some of the critical theory researchers who use spirituality as their ideological approach to research. Dantley also argues, and rightly so, that spirituality among African American educators and researchers is trivialized and labeled irrelevant, unscientific and inappropriate from the standpoint of a positivist approach. He proposes diverse and plural frameworks that create appropriate foundations that adequately depict social reality. In that sense, spirituality is an epistemic that deconstructs the linear logic of Western rationality. In chapter 7, Stephen Hancock sees schools as microcosms of society that contribute to selfdenigration by failing to appeal to the spirit that constitutes the consciousness of diverse students. Spirituality is perceived as critical resistance pedagogy and a research tool which leads to emancipation, praxis-oriented inquiry, epistemological neutrality, transformative social action, and intellectual peace. Hancock associates educational praxis with the creation and promotion of holistic education.

Teacher education is an important $\operatorname{cog}$ in the education system because of its role in preservicing and in-servicing teachers. In chapter 8, Richard Milner advises teacher educators to examine their pedagogical practices which impact teachers and students. Like the other authors in this book, he successfully utilizes narrative inquiry to examine how curricular decisions to teach about race tend to focus on Eurocentric ideology while neglecting the contributions of Black teacher educators. In addition, Milner also uses self-reflections to examine his own research, curriculum development and pedagogical practices. Milner's personal narratives reveal how his African American everyday racialized stories outside the classroom affect his approach to teaching courses designed for teacher education students. Self-reflection has connections to action and transformative research. Transformation of the whole education system is the common thread that comes across in all the chapters as the overall aim of the book. Beverly Cross takes the debate on marginalization of Black teachers further in chapter 9. She notes that in the US, the demographic imperative, which refers to significant changes in the racial, ethnic, and language groups, entails more diverse schools and classrooms, which in turn requires teachers from diverse backgrounds. The mismatch between a White teaching force and a diverse student population is not healthy for minority students' academic achievement and success. Cross proposes enhancing the voices of Black teachers by involving them in educational research, debate, dialogue and decision making in teacher preparation programs. The absence or underrepresentation of Black teachers in educational programs perpetuates the undervaluing of the cultural knowledge of "others". Using narratives from the margins she concludes that reframing and redesigning an inclusive and culturally sensitive teacher preparation program is a necessity for equalizing academic achievement in a diverse society.

By and large, Milner's edited book provides a vision for progress. The debates and arguments in the book are liberating and empowering. The book is grounded in informative and substantial research, as well as a wide range of related literature. The use of self reflections and narratives from the margin bring the voices of the neglected into the well crafted and engaging transformative and empowering discourse. For example, Toshalis, Milner, DaSilver and Rose, Irizarry and Raible, and James have remarkable narratives from teachers and students. The 
voices help the reader to understand the effect of culture on identity formation and perceptions from those who are affected. The reader can empathize with those whose cultures are misrepresented and marginalized in the schooling system. The unheard voices are a guide to our understanding of the reasons behind the culture of classroom silence (Bosacki, 2005). Milner, as the editor of Culture, Curriculum, and Identity in Education has ably put together a team of authors who have ample knowledge and research experience in the area of cultural diversity and its effect on identity formation and curriculum development and implementation. The book draws our attention to well-researched social and cultural situations that exist in diverse societies and their implications for academic success/failure.

The topics covered have implications for curriculum design and transformation, pedagogical practices, theory development and research. The overarching pointer throughout the book is the disconnection between mostly White teachers with limited experience and training and the teaching of students from minority groups. The lack of experience and adequate preservice preparation for these teachers are the reasons for poor academic performance of African American, Hispanic, and American Native students. The idea that is consistent throughout the book is that schools should be empowering for all students and that teachers should be multicultural workers working in multicultural schools and language and curricula should be inclusive.

This book hss a wealth of research that is conceptually and theoretically informative, especially to educators and researchers who desire to engage in dialogical conversations that empower marginalized teachers, teacher educators and visible minority students by granting them their subjective and objective voices. The authors encourage educators to create socially and culturally connected classrooms that foster students' voices by promoting both critical reflection and self-expression. This is a multidisciplinary text that draws from a variety of disciplines such as social science research methods, social psychology, sociology and education. Culture, curriculum, and identity in education will appeal to a cross-section of students, educators and researchers who work with visible minority teachers and students from diverse cultural backgrounds. Throughout the book, practical classroom implications, and constructive guidelines for fostering dialogue, voice and curriculum transformation, cultural sensitivity and positive pedagogical practices are outlined and clearly explained. Thus the book is an invaluable text for teachers who are in pursuit of creating and recreating classrooms that engage students in inter-subjective dialogue and educational programs that draw on other cultures to build an integrated, and transformational learning model (Shizha, 2005).

\section{Edward Shizha}

Wilfred Laurier University (Brantford) 


\section{References}

Bosacki, S. L. (2005). The Culture of Classroom Silence. New York: Peter Lang.

Shizha, E. (2005). Review of Bosacki Sandra (2005). "The culture of classroom silence.” In

Education Review: A Journal of Book Reviews (November 30). Available at http://edrev.asu.edu/reviews/rev443.htm 